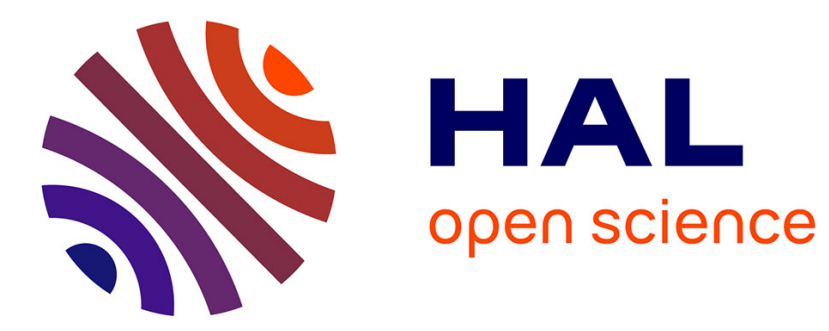

\title{
PULSED LASER EXCITATION AND OPTICAL DETECTION OF RAYLEIGH WAVES ON A METALLIC SPHERE
}

\author{
X. Jia, D. Royer, G. Quentin
}

\section{- To cite this version:}

X. Jia, D. Royer, G. Quentin. PULSED LASER EXCITATION AND OPTICAL DETECTION OF RAYLEIGH WAVES ON A METALLIC SPHERE. Journal de Physique IV Proceedings, 1992, 02 (C1), pp.C1-789-C1-792. 10.1051/jp4:19921172 . jpa-00251133

\section{HAL Id: jpa-00251133 https://hal.science/jpa-00251133}

Submitted on 1 Jan 1992

HAL is a multi-disciplinary open access archive for the deposit and dissemination of scientific research documents, whether they are published or not. The documents may come from teaching and research institutions in France or abroad, or from public or private research centers.
L'archive ouverte pluridisciplinaire HAL, est destinée au dépôt et à la diffusion de documents scientifiques de niveau recherche, publiés ou non, émanant des établissements d'enseignement et de recherche français ou étrangers, des laboratoires publics ou privés. 


\title{
PULSED LASER EXCITATION AND OPTICAL DETECTION OF RAYLEIGH WAVES ON A METALLIC SPHERE
}

\author{
X. JIA, D. ROYER* and G. QUENTIN \\ G.P.S., Université Paris 7, Tour 23, 2 place Jussieu, F-75251 Paris cedex 05, France \\ *Laboratoire Ondes et Acoustique, ESPCI, 10 rue Vauquelin, F-75231 Paris cedex 05, France
}

\begin{abstract}
Résumé. Nous avons engendré et détecté optiquement des ondes de Rayleigh sur une sphère métallique. La source est un laser YAG fonctionnant en régime pulsé. Le déplacement mécanique est mesuré, au point diamétralement opposé au point d'impact, par une sonde interférométrique hétérodyne. Les fréquences de résonance d'une sphère en acier inoxydable de diamètre $20 \mathrm{~mm}$ ont été déduites directement du spectre du signal ainsi que les variations de la vitesse de groupe. Les résultats expérimentaux sont en bon accord avec les valeurs prévues par l'analyse.
\end{abstract}

Abstract. Rayleigh waves have been optically generated and detected on a metallic sphere. The source was a pulsed YAG laser. The mechanical displacement was measured, at a point diametrically opposite to the laser impact, by an heterodyne interferometer. The resonance frequencies of stainless-steel sphere of diameter $20 \mathrm{~mm}$ was rapidly obtained from the fast Fourier transform of the probed signal. The variation of the group velocity was also deduced from the resonance spectrum. Experimental results agree with the analysis.

\section{INTRODUCTION}

Surface acoustic waves travelling along curved surfaces have been an interesting subject in geophysics and acoustics since a long time [1,2,3]. In acoustic scattering field, targets like cylinders or spheres are usually excited by acoustic waves incident from the ambient liquid. The resonances are physically explained in terms of surface acoustic waves which, at an eigenfrequency, match phases during repeated circumnavigation around the target. The constructive interferences, establish the resonance of the target.

We describe here an experimental approach to study surface acoustic waves on axisymmetrical objects with pulsed laser excitation. The use of transient generation permits not only identification of different types of circumferential waves via their arrival times but also broadband frequency analysis. The elastic waves are investigated without any mechanical contact with the aid of an optical interferometric probe [4]. In a previous work [5] this noncontact method has been used to study the propagation of Lamb waves in plates and cylindrical shells as well as surface waves in cylinders and spheres.

In this paper we discuss only the generalized Rayleigh acoustic waves on free metallic spheres. The use of a fast Fourier transform of the optically probed circumferential signals allows us to establish the resonance spectrum of Rayleigh waves on spheres. The group velocity of Rayleigh waves is also deduced.

\section{EXPERIMENTAL SET-UP}

The experimental set up is shown in Fig.1. The YAG laser $(\lambda=1.06 \mu \mathrm{m})$ providing optical pulses of energy $100 \mathrm{~mJ}$ and of a duration $10 \mathrm{~ns}$ is focused into a spot of a diameter about $2 \mathrm{~mm}$ on a stainless 
steel sphere. The resulting power density of $100 \mathrm{MW} / \mathrm{cm}^{2}$ produces a slight material evaporation (ablation regime) which creates consequently a stress normal to the surface. The propagation of the launched elastic waves is investigated by means of an optical heterodyne interferometer. This probe, associated with a broadband electronic detection, measures the normal mechanical displacement with a sensitivity of $0.5 \AA$ for a $30 \mathrm{MHz}$ detection bandwidth [4]. The probed signals are sampled and averaged by a digital oscilloscope and then sent to a micro-computer.

\section{RESULTS AND DISCUSSION}

Fig. 2 shows the transient mechanical displacement, detected on a stainless steel sphere of diameter $20 \mathrm{~mm}$ by the optical probe at the pole diametrically opposite to the laser impact (Fig.1). The echoes correspond to the propagation of surface waves around the sphere, diverging from one pole and converging towards the other and so on $[5,6]$. The dominant generation of surface waves of Rayleigh type is explained by the fact that the photoacoustic source is located close to the material surface and consequently most of the photothermal energy is converted into surface acoustic waves instead of bulk waves [7]. As clearly seen in the time signals (Fig. 2), the Rayleigh waves on a sphere exhibit a dispersive effect: the longer the propagation path, the wider the pulses. This effect, which does not appears for Rayleigh waves travelling on a plane, is due to the curvature of the surface [6] and has been also observed on cylinders $[5,8]$.

Fig.3 displays a fast Fourier transform of the whole signal in Fig.2. The envelope of the resonance spectrum (bottom curve) is similar to the spectrum of the first echo (top curve). The positions of the maxima in the frequency spectrum correspond to the different orders $n$ of resonance of the Rayleigh waves on the sphere. The longitudinal and shear wave velocities in the sphere have been measured as $5.99 \mathrm{~km} / \mathrm{s}$ and $3.29 \mathrm{~km} / \mathrm{s}$. Table I gives the 20 first resonance frequencies measured from this spectrum as well as the calculated values [9]. The absence of the mode $n=0$ is explained by the fact that this mode corresponds to a radial vibration and not to a circumferential surface wave. The discrepancy of about $1 \%$ observed between theoretical and experimental results arises probably from the frequency resolution of the discrete FFT limited by the $10 \mathrm{kHz}$ sampling frequency of the signal. The results demonstrate that, for resonance studies of surface acoustic waves, the present method is much faster than the swept frequency measurement [9] requires:

If $n$ and $n+1$ are two successive resonance modes, then the condition of constructive interference

$$
\Delta k=k_{n+1}-k_{n}=\frac{(n+1)}{a}-\frac{n}{a}=\frac{1}{a}
$$

where $k_{n}$ is the wave number of $n$th modal resonance and a the radius of the sphere. Assuming that $f_{n}$ is the $n$th resonance frequency, we deduce from (1) the following formula [9]:

$$
\frac{\Delta \omega}{\Delta k}=\frac{2 \pi\left(f_{n+1}-f_{n}\right)}{\Delta k}=2 \pi \mathrm{a} \Delta f \underset{\Delta k \rightarrow 0}{\longrightarrow} V_{g}
$$

which gives approximately the group velocity only from the frequency difference $\Delta f[9]$. The experimental values $\mathrm{Vg}_{\mathrm{g}}$, deduced from this method, are plotted versus the product of shear wavenumber by sphere radius $\left(k_{\mathrm{t}} \mathrm{a}\right)$ in Fig.4. The decrease of the group velocity with frequency is slight. However it confirms the observation of the low frequency components arriving first (Fig.2). The discrepancy from the calculated dispersion curve comes from the imprecision in the measurement of the resonance frequencies.

\section{CONCLUSION}

Rayleigh waves on metallic spheres have been generated by a pulsed laser and detected by an optical interferometer. The Fourier transform of the probed signal allows us to build up rapidly the resonance spectrum over a broad frequency range. The group velocity of the Rayleigh waves is deduced quantitatively from the resonance spectrum. The experimental results demonstrate that the laser ultrasonic techniques is helpful for characterizing surface acoustic waves on elastic scatterers. 


\section{REFERENCES}

1. W.M. Ewing, W.S. Jardetzky and F. Press, Elastic Waves in Layered Media (McGraw-Hill, New York, 1957)

2. Überall, in Physical Acoustics, edited by W.P. Mason and R.N. Thurston (Academic Press, New York, 1973), Vol.10, Chap.1

3. J.P. Sessarego, J. Sageloli, C. Gazanhes and J. Léandre, in La Diffusion Acoustique, edited by N. Gespa (CEDDCAR, Paris, 1987), Chap. 20, 519

4. D. Royer and E. Dieulesaint, 1986 IEEE Ultrasonics Symp. Proc. , 527 (1986)

5. X. Jia, Thèse de Doctorat de l'Université P. et M. Curie (Paris, 1988)

6. D. Royer, E. Dieulesaint, X. Jia and Y. Shui, Appl. Phys. Lett. 52, 706 (1988)

7. L.R.F. Rose, J. Acout. Soc. Am. 75, 723 (1984)

8. I.A. Viktorov, Rayleigh and Lamb waves (Plenum Press, New York, 1967), 33

9. Y. Shui, D. Royer, E. Dieulesaint and Z. Sun, 1988 IEEE Ultrasonics Symp. Proc., 343 (1988)

10. G. Quentin, A. Derem and B. Poirée, J. Phys. France 50, 1943 (1989)

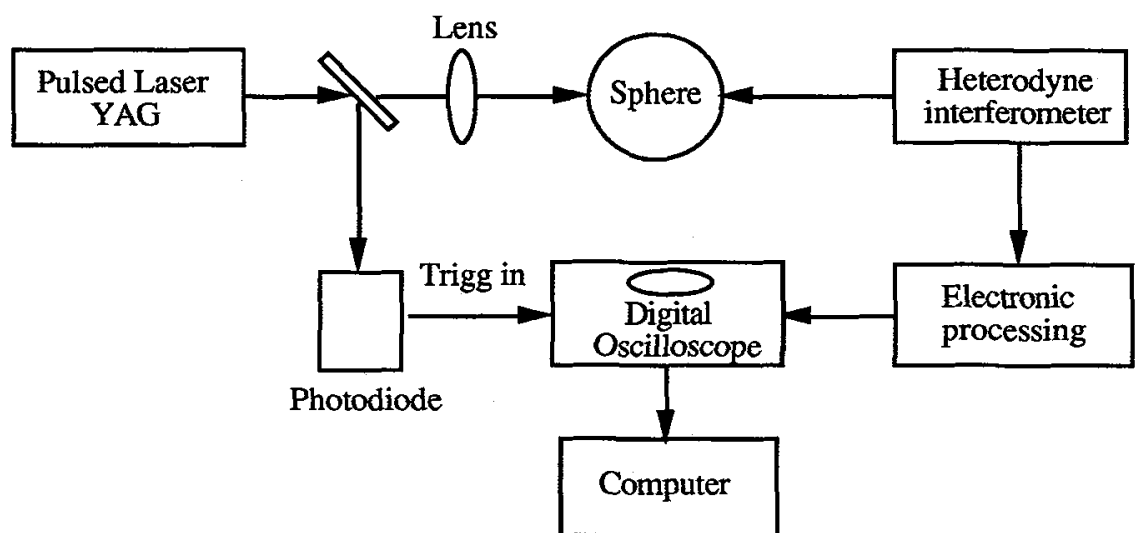

Fig.1. Experimental arrangement of pulsed laser generation and interferometric detection of surface acoustic waves on a sphere

\begin{tabular}{|c|c|c|c|c|c|}
\hline & \multicolumn{2}{|c|}{ Resonance frequency (MHz) } & & \multicolumn{2}{|c|}{ Resonance frequency (MHz) } \\
\hline $\mathrm{n}$ & Measured & Predicted & $\mathrm{n}$ & Mesured & Predicted \\
\hline 1 & --- & -- & 11 & 0.625 & 0.6220 \\
\hline 2 & 0.137 & 0.1384 & 12 & 0.674 & 0.6716 \\
\hline 3 & 0.205 & 0.2058 & 13 & 0.723 & 0.7210 \\
\hline 4 & 0.264 & 0.2636 & 14 & 0.771 & 0.7703 \\
\hline 5 & 0.322 & 0.318 & 15 & 0.820 & 0.8195 \\
\hline 6 & 0.371 & 0.3700 & 16 & 0.869 & 0.8687 \\
\hline 7 & 0.420 & 0.4213 & 17 & 0.918 & 0.9178 \\
\hline 8 & 0.469 & 0.4720 & 18 & 0.967 & 0.9668 \\
\hline 9 & 0.527 & 0.5223 & 19 & 1.016 & 1.0158 \\
\hline 10 & 0.576 & 0.5722 & 20 & 1.065 & 1.0648 \\
\hline
\end{tabular}

Table I. Experimental and theoretical resonance frequencies of Rayleigh waves on a stainless-steel sphere $\left(V_{L}=5.99 \mathrm{~km} / \mathrm{s}, V_{T}=3.29 \mathrm{~km} / \mathrm{s}\right)$ of diameter $20 \mathrm{~mm}$ 


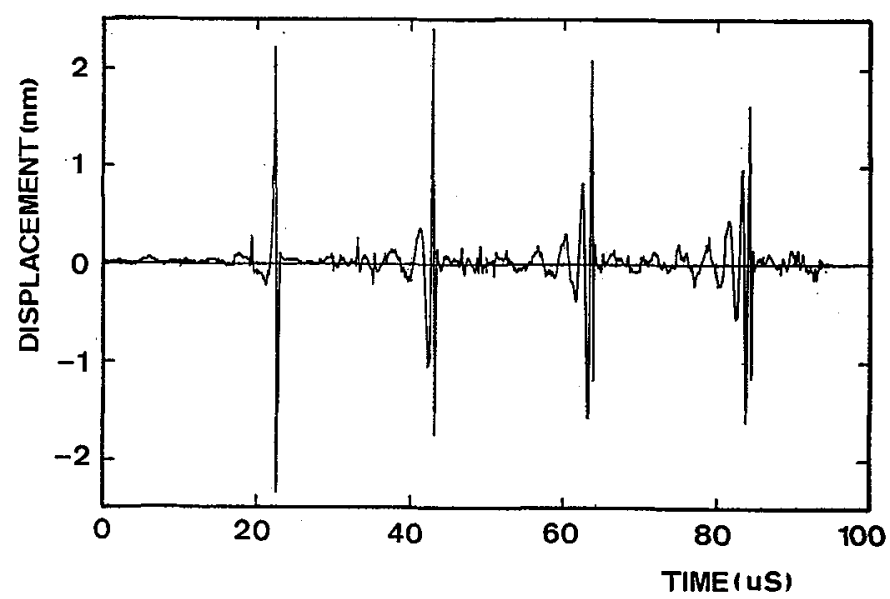

Fig. 2 Optically probed transient displacement of Rayleigh waves on a stainless steel sphere of diameter $20 \mathrm{~mm}$.

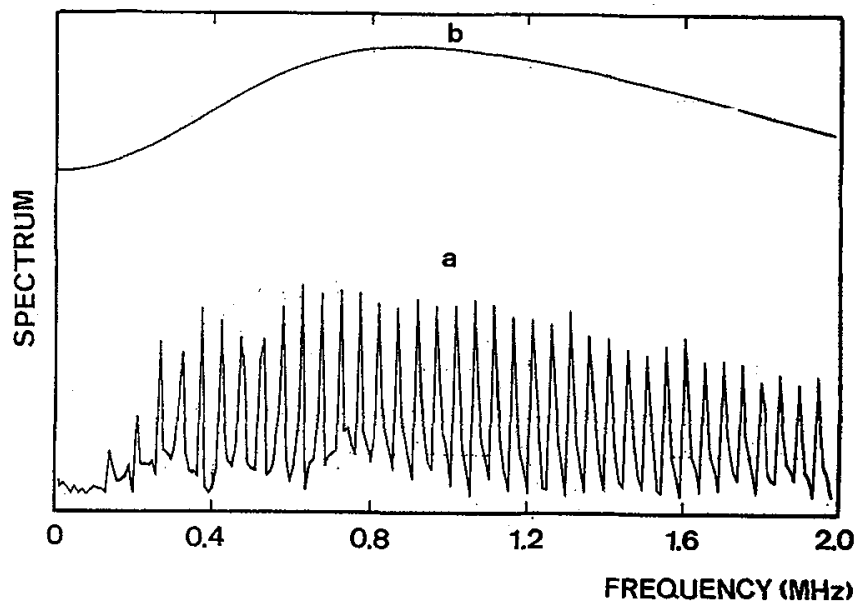

Fig. 3 Fourier transforms of the whole signal in Fig. 2 (a) and of the first echo (b).

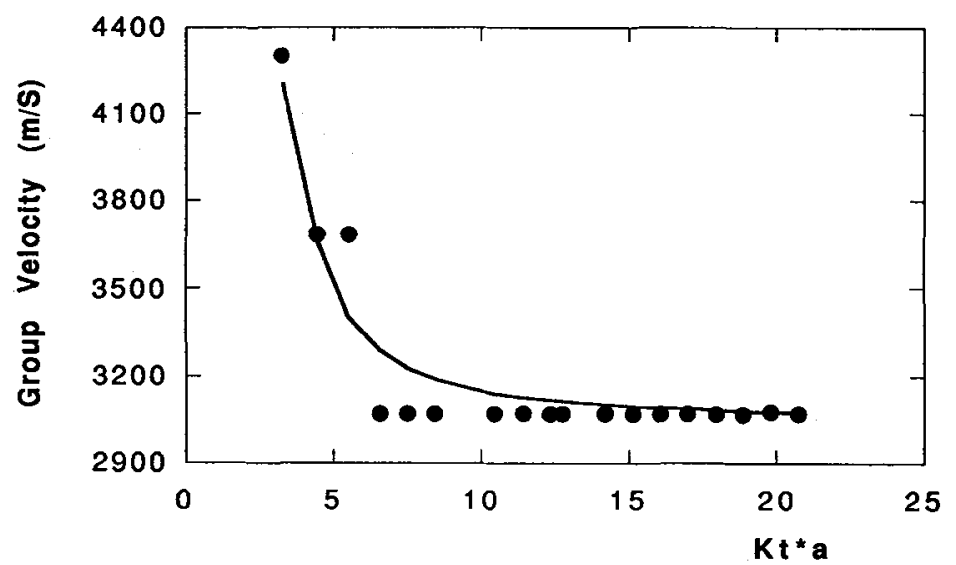

Fig. 4 Theoretical and experimental (0) group velocities of Rayleigh waves on a stainless steel sphere versus the product of shear wavenumber by sphere radius 